\title{
Sustainable Synthesis of Gold Nanoparticles and its Antidiabetic Activity of Anacardium occidentale Root Extract
}

\author{
A. LEEMAROSE ${ }^{1 *}$, F. JANEETA PRIYA ${ }^{2}$ and S. VIDHYA ${ }^{3}$ \\ 1,2,3,PG and Research Department of Chemistry, Holy Cross College, \\ Affiliated to Bharathidasan University, Tiruchirappalli-620002, Tamil Nadu, India. \\ ${ }^{*}$ Corresponding author E-mail: leemarose25@gmail.com \\ http://dx.doi.org/10.13005/ojc/370216
}

(Received: February 16, 2021; Accepted: April 18, 2021)

\begin{abstract}
Nanoparticles are being considered as elemental building blocks of nanotechnology. The green synthesis of gold nanoparticles using the aqueous root extract of Anacardium occidentale by bio-reduction of Auric chloride solution was investigated in the current study. The synthesized gold nanoparticles were characterized using UV-Visible spectroscopy, Fourier Transform Infrared spectroscopy and Scanning Electron Microscope. In UV, the absorbance peak was observed at $531 \mathrm{~nm}$, FTIR spectrum shows the wavelength range from $464.27 \mathrm{~cm}^{-1}$ to $3364.51 \mathrm{~cm}^{-1}$ and SEM image showed that gold nanoparticles are in spherical shape. Then, the biosynthesized gold nanoparticles examined for the antidiabetic and antioxidant activities and the result outcome with better percentage of potential.
\end{abstract}

Keywords: Green synthesis, Gold nanoparticle, Anacardium occidentale, Auric chloride, UV, FTIR, SEM, Antidiabetic, Antioxidant.

\section{INTRODUCTION}

Diabetes is a metabolic disease which causes the blood sugar level to raise thus by complicating the daily metabolism of life. Phytoconstituents plays a good role in controlling the side effects but the reason to be concerned about it is the time taken and its slow action. So to deal with it, we are conjoining the nanoparticles with these substances so as to be eco-friendly, to increase the efficiency of insulin and also to increase the normally metabolism of human body ${ }^{1-4}$. The nanoparticles are the one which are very tiny and are of the size 1 to $100 \mathrm{~nm}$ with numerous applications which are synthesized by three methods-which are Physical, Chemical and Biological method ${ }^{5-7}$. The nanoparticle synthesis using phyto extracts have been creating waves of spirit of eco friendliness and its application in many fields specially concentrating in medical field ${ }^{8-10}$. The gold nanoparticles with $1 \mathrm{~nm}$ to $8 \mathrm{~nm}$ are used in diagnosis of heart diseases and cancers as the biomarkers, as good biological imaging applications. To investigate furthermore applications in gold nanoparticles, it is synthesized via green method from Anacardium occidentale whose common name is cashew plant. It contain riboflavin, $\mathrm{E}, \mathrm{C}$ and $\mathrm{K}$ vitamins, antifungal, antiparasitic and anti-inflammatory properties ${ }^{10-14}$.

This is an Open Access article licensed under a Creative Commons license: Attribution 4.0 International (CC- BY). Published by Oriental Scientific Publishing Company @ 2018

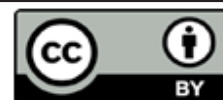


The aim of this investigation to study the anti-oxidant and antidiabetic activity of the gold nanoparticles synthesized from Anacardium occidentale.

\section{EXPERIMENTAL METHODS}

\section{Preparation of the plant sample}

The fresh roots of the Anacardium occidentale were collected from Panruti of Cuddalore district, Tamilnadu. They are washed well with normal water and then with double distilled water. After the collection, the roots were shade dried well and made into the powder sample ${ }^{15-16}$. The aqueous extract was prepared from the dried sample by boiling it with water which is the universal solvent, it was then filtered by using whatmann no 40 filter paper and the stock solution was collected in a brown bottle and is then refrigerated.

\section{Synthesis of gold nanoparticles}

The stock solution was prepared from the dried roots of Anacardium occidentale using water as the solvent for the preparation of the aqueous extract. Auric chloride solution was prepared by weighing for which the concentration ought to be $1 \mathrm{Mm}$ and is dissolved in double dissolved water in a $50 \mathrm{~mL}$ standard flask. From the prepared auric chloride solution, various concentrations of the plant sample were added to the auric chloride in drop by drop manner and the optimum concentration was fixed. At about 30 seconds after the addition, the colour of the solution changes from pale yellow to ruby red colour indicating the formation of stable gold nanoparticles.

\section{Characterizations of Gold Nanoparticle UV-Visible spectra analysis}

The main purpose of using UV-Visible spectroscopy is to determine the optical properties of the solution. This concept is mainly based on the Beer-Lambert law which states the absorbance is directly proportional to the concentration of absorbing particles present in the solution. The formations of the nanoparticles synthesized were confirmed by the measurement of the SPR band using the U-2900 spectrophotometer with $1 \mathrm{~cm}$ path length in a $2 \mathrm{~mL}$ quartz cuvette.

\section{FTIR}

Fourier-transform infrared spectroscopy is usually done to analyse the various bioconstituents present in the plant sample, so that it is easy to identify what type of compounds present in the extract $^{7-8}$. By doing this FTIR measurement, the molecules that act as the reducing and stabilising agents are identified.

\section{Scanning Electron Microscope}

The Scanning Electron Microscope is employed for the determination of the morphology of the synthesized metal nanoparticles. The principle of the SEM is same as that of the optical microscope, but it measures the electrons scattered from the sample rather than that of the photons. The working of the SEM is by the use narrow beam of highly energytic electron at the surface of the sample to give the signals which are inturn giving the information about the topographical, morphological and compositional informations.

\section{Antioxidant activity (DPPH free radical scavenging activity) determination}

Here the antioxidant activity of gold nanoparticles was studied using the DPPH stability by examining the scavenging effect on the free radical. About $40 \mu \mathrm{l}$ of the gold nanoparticles were added to the DPPH solution. The mixture was shaken vigorously and left undisturbed for $5 \mathrm{~min}$ and using the spectrophotometer, the absorbance was measured at $540 \mathrm{~nm}$. A graph was plotted using percent inhibition versus concentration curve and the inhibiton for $50 \%$ was determined.

\section{ALPHA-Glucosidase inhibitory assay}

The $\alpha$-glucosidase activity of the synthesized gold nanoparticle was studied. The solution of p-nitrophenyl glucopyranoside ( $p-N P G$ ) was added to $\mathrm{pH}$ 6.9. $100 \mu \mathrm{L}$ of $\alpha$-glucosidase $(1.0 \mathrm{U} / \mathrm{mL})$ and the solution used were all incubated previously for 10 min at various concentrations of the nanoparticles. The reaction is started by adding the nanoparticles dissolved in buffer. It was then incubated for $20 \mathrm{~min}$ at temperature $37^{\circ} \mathrm{C}$ and the reaction was brought to an end by adding sodium carbonate. The yellow colour of the solution determines activity. Here also the inhibition was studied by the inhibition formula. The $50 \%$ inhibition of enzyme activity was derived graphically. 


\section{RESULTS AND DISCUSSION}

\section{Qualitative analysis}

The quantitative analysis of Anacardium occidentale root extract was done and the results are tabulated in Table 1. The Anacardium occidentale root extract shows the following list of phytoconstituents like resin, phenol, quinines, glycosides, flavanoids, sapanoids, proteins etc.

Table 1: Qualitative analysis of Anacardium occidentale root extract

\begin{tabular}{cccc}
\hline Sl.No & Phytoconstituents & Name of the plant & Presence \\
\hline 1 & Tannin & Anacardium occidentale & ++ \\
2 & Emodin & Anacardium occidentale & - \\
3 & Quinones & Anacardium occidentale & ++ \\
4 & Coumarin & Anacardium occidentale & - \\
5 & Flavanoids & Anacardium occidentale & + \\
6 & Xanthoprotein & Anacardium occidentale & - \\
7 & Anthocyanin & Anacardium occidentale & + \\
8 & Alkaloid & Anacardium occidentale & + \\
9 & Proteins & Anacardium occidentale & + \\
10 & Carbohydrate & Anacardium occidentale & + \\
11 & Terpenoids & Anacardium occidentale & + \\
12 & Phlobatanin & Anacardium occidentale & - \\
13 & Leucoanthocyanin & Anacardium occidentale & - \\
14 & Terpenoids & Anacardium occidentale & + \\
15 & Saponoid & Anacardium occidentale & ++ \\
16 & Resin & Anacardium occidentale & + \\
17 & Anthroquinone & Anacardium occidentale & - \\
18 & Carbohydrate & Anacardium occidentale & + \\
\hline & & &
\end{tabular}

\section{Visual observation}

The gold nanoparticles were synthesised by taking the auric chloride solution of $1 \mathrm{mM}$ concentration and thus by gradually adding the Anacardium occidentale Root extract to it. The colour changes from colourless to ruby red colour. This colour remained unchanged for more than a month which was periodically checked at regular intervals.

\section{UV-Visible spectroscopy}

The absorbance peak for gold nanoparticles was observed at $531 \mathrm{~nm}$. These are due to the colour change in the nanoparticles which was observed due to the shift resulted from the Surface Plasmon Resonance (SPR) band. Thus, by the periodic observation by using UV-Visible spectroscopy, the Bio-reduction of the nanoparticles due to which the auric chloride changed its colour from colorless to ruby red.

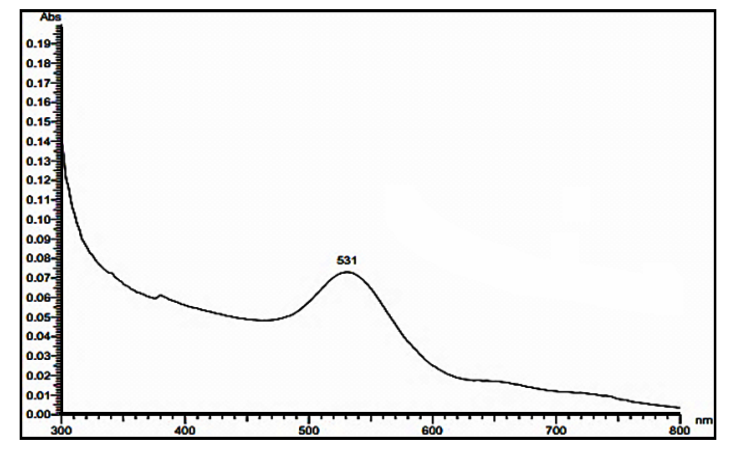

Fig. 1. UV-Visible spectra of gold nanoparticles FTIR

Fourier-transform infrared spectroscopy is usually done to analyse the various bioconstituents present in the Anacardium occidentale Root extract and to identify what type of compounds present in the extract which are acts as the reducing and stabilizing agents.

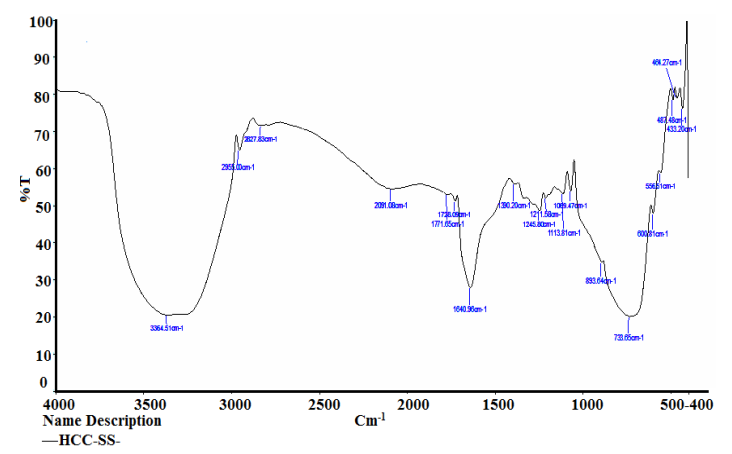

Fig. 2. FTIR of Anacardium occidentale root extract

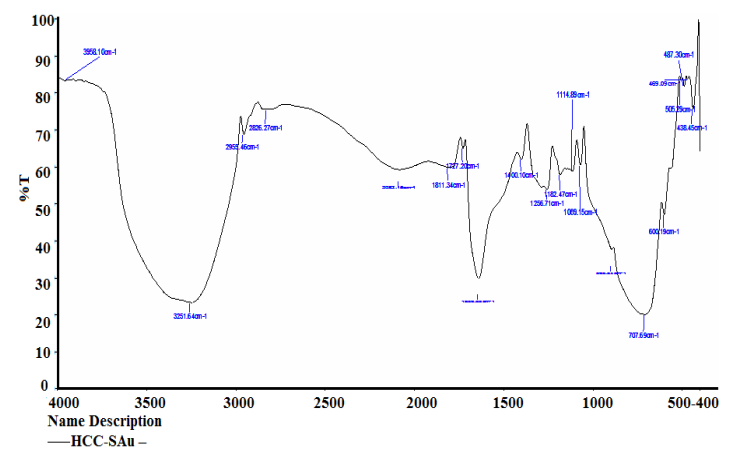

Fig. 3. FTIR spectrum of synthesised gold nanoparticles

The Table 2 shows the comparison of FTIR regions of the Anacardium occidentale root extract and the synthesised gold nanoparticles. Due to the presence of these functional groups the root extract of Anacardium occidentale shows good therapeutic applications and it is especially used in the treatment of diabetes. 
Table 2: Comparision of FTIR of the Anacardium occidecntal root extract and gold nanoparticle

\begin{tabular}{|c|c|c|}
\hline & FTIR of the Anacardium occidentale root extract & FTIR of the gold nanoparticle \\
\hline $\operatorname{BAND}\left(\mathrm{cm}^{-1}\right)$ & FUNCTIONAL GROUPS & FUNCTIONAL GROUPS \\
\hline $3364.31 \mathrm{~cm}^{-1}$ & $\mathrm{NH}$ strectching aliphatic $1^{\circ}$ amine & $\mathrm{NH}$ strectching aliphatic $1^{\circ}$ amine \\
\hline $2933 \mathrm{~cm}^{-1}$ & $\mathrm{CH}$ stretching alkane & - \\
\hline $2827 \mathrm{~cm}^{-1}$ & $\mathrm{CH}$ stretching aldehyde & - \\
\hline $2001 \mathrm{~cm}^{-1}$ & $\mathrm{~N}=\mathrm{C}=\mathrm{C}$ carbodiamide & $\mathrm{N}=\mathrm{C}=\mathrm{C}$ carbodiamide \\
\hline $1728 \mathrm{~cm}^{-1}$ & Weak $\mathrm{CH}$ bending aromatic compound & Weak $\mathrm{CH}$ bending aromatic compound \\
\hline $1390 \mathrm{~cm}^{-1}$ & $\mathrm{CH}$ bending aldehyde & $\mathrm{CH}$ bending aldehyde \\
\hline $1069 \mathrm{~cm}^{-1}$ & $\mathrm{~S}=\mathrm{O}$ stetching sulfoxide & $\mathrm{S}=\mathrm{O}$ stetching sulfoxide \\
\hline $1211 \mathrm{~cm}^{-1}$ & C-O stretching vinyl ether & C-O stretching vinyl ether \\
\hline $1245 \mathrm{~cm}^{-1}$ & Medium C-N stretching & Medium C-N stretching \\
\hline $1110 \mathrm{~cm}^{-1}$ & Strong C-O stetching aliphatic ether & Strong C-O stetching aliphatic ether \\
\hline $813 \mathrm{~cm}^{-1}$ & Medium $\mathrm{C}=\mathrm{C}$ bending alkene & Medium $\mathrm{C}=\mathrm{C}$ bending alkene \\
\hline
\end{tabular}

\section{Scanning Electron Microscope}

The SEM was performed for the analysis of the size, shape and surface morphology and it reveals that the synthesized gold nanoparticles are of spherical shape. Fig. 4, shows the synthesized gold nanoparticles were more or less uniform in size and shape. The SEM images of the synthesised gold nanoparticles using the Anacardium occidentale root extract shows the surface topography and it reveals that the synthesised gold nanoparticles are of spherical shape. The spherical shapes are clearly shown in the figure below.

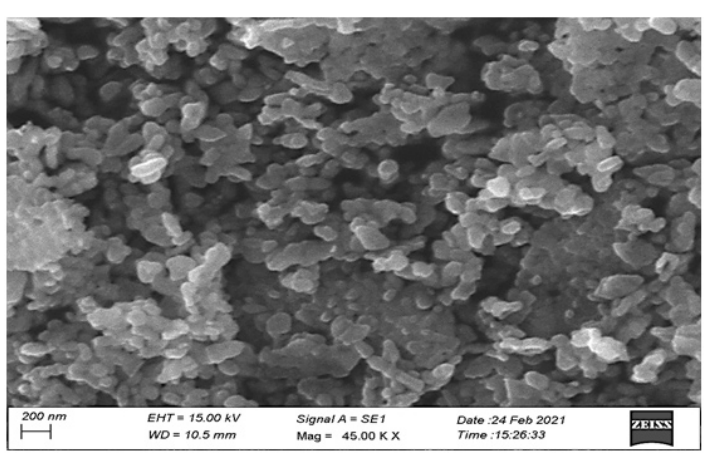

Fig. 4. SEM image of the gold nanoparticles

\section{Antioxidant Activity of the Gold Nanoparticles by DPPH Method}

The result showed that the gold nanoparticles synthesised using Anacardium occidentale root extract had better percentage antioxidant activities at high concentrations when compared with ascorbic acid (Table 3 ). The compound showed $74 \%$ activity at concentration $100 \mu \mathrm{g} / \mathrm{mL}$ while ascorbic acid gave $94.69 \%$ at the same concentration.
Table 3: Antioxidant activity of the AuNP

\begin{tabular}{llll}
\hline S.No & Concentrations & \multicolumn{2}{c}{ Scavenging Effect (\%) } \\
& & Sample & Ascorbic acid \\
\hline 1 & $20(\mu \mathrm{g} / \mathrm{mL})$ & $60 \pm 0.75$ & $41.60 \pm 1.37$ \\
2 & $40(\mu \mathrm{g} / \mathrm{mL})$ & $65 \pm 0.88$ & $66.85 \pm 1.35$ \\
3 & $60(\mu \mathrm{g} / \mathrm{mL})$ & $69 \pm 0.12$ & $76.74 \pm 1.40$ \\
4 & $80(\mu \mathrm{g} / \mathrm{mL})$ & $71 \pm 0.52$ & $82.34 \pm 1.43$ \\
5 & $100(\mu \mathrm{g} / \mathrm{mL})$ & $74 \pm 0.48$ & $94.69 \pm 1.58$ \\
\hline & & & \\
\hline
\end{tabular}

Fig. 5. Antioxidant activity of AuNPs

\section{Antidiabetic Activity of gold}

In vitro $\alpha$-glucosidase Inhibitory assay

The percentage of the inhibition of gold nanoparticle at $20-100 \mu \mathrm{g} / \mathrm{mL}$ concentrations of the root extract showed a dose dependent increase in percentage inhibition. The percentage inhibition varied from $47+0.63$ to $79+0.26$ for the highest concentration to the lowest concentration.

Table $5: \alpha$-glycosidase inhibitory activity of AuNPs

\begin{tabular}{cccc}
\hline S. No & Concentrations & \multicolumn{2}{c}{ Alpha glycosidase (\%) } \\
& & sample & Acarbose \\
\hline 1 & $20(\mu \mathrm{g} / \mathrm{mL})$ & $47 \pm 0.65$ & $72.70 \pm 1.40$ \\
2 & $40(\mu \mathrm{g} / \mathrm{mL})$ & $58 \pm 0.59$ & $62.34 \pm 1.37$ \\
3 & $60(\mu \mathrm{g} / \mathrm{mL})$ & $60 \pm 0.59$ & $75.48 \pm 1.42$ \\
4 & $80(\mu \mathrm{g} / \mathrm{mL})$ & $63 \pm 0.42$ & $84.54 \pm 1.47$ \\
5 & $100(\mu \mathrm{g} / \mathrm{mL})$ & $79 \pm 0.26$ & $95.68 \pm 1.38$ \\
\hline
\end{tabular}




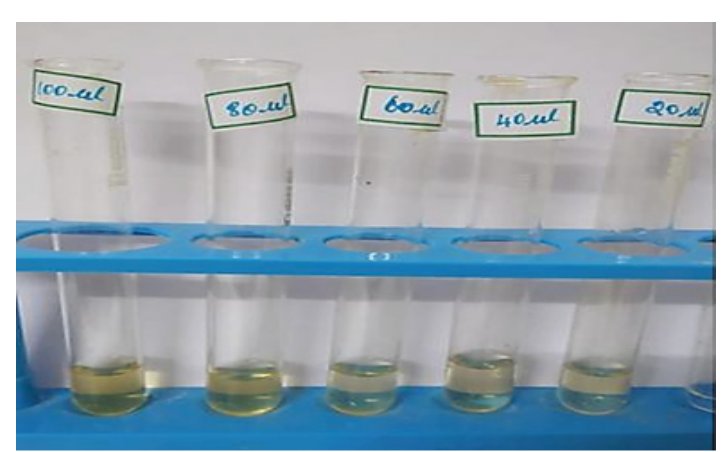

Fig. 6. $\alpha$-glycosidase inhibitory activity of AuNPs

\section{CONCLUSION}

The green synthesis of nanoparticles caught the attention of everyone due to its reduced toxicity and its eco-friendly approach. The green synthesis of gold nanoparticle using Anacardium occidentale root extract is an effective green method by which the phytoconstituents are potentially utilized to its maximum ability. Qualitative analysis was done using the Anacardium occidentale root extract and various phytoconstituents like tannin, saponin, phenol, quinine, flavanoid, terpenoid, carbohydrate, alkaloid in it. Bio-synthesis of gold nanoparticles was done using Anacardium occidentale root extract.The UV absorpation peak obtained at $533 \mathrm{~nm}$. FTIR analysis done to found out the functional group responsible for the reductant for the formation of the gold nanoparticle SEM analysis showed the spherical shape of the gold nanoparticles. The investigation of antioxidant activity of the gold nanoparticle resulted in $74 \%$ potential. The antidiabetic activity of the gold nanoparticle has potential at $79 \%$ in In vitro $\alpha$-glucosidase inhibitory assay.

\section{ACKNOWLEDGMENT}

This research did not receive any specific grant from funding agencies in the public, commercial, or not-for-profit sectors.

\section{Conflicts of Interest}

The authors declare no conflict of interest.

\section{REFERENCE}

1. Christian P.; Von der Kammer F.; Baalousha M.; Hofmann T, "Nanoparticles: structure, properties, preparation and behaviour in environmental media", Ecotoxicology., 2008, 17(5), 326-43.

2. Paz Elia.; Raya Zach.; Sharon Hazan.; Sofiya Kolusheva.; Ze'evPorat and Yehuda Zeiri, "Green synthesis of gold nanoparticles using plant extract as reducing agents", International Journal of Nanomedicine., 2014, 9, 4007-4021.

3. Govindasamy Balasubramani.; Rajendiran Ramkumar.; Naryanaswamy Krishnaveni.; Rajamani.; Sowmiya.; Paramasivam Deepak.; Dhayalan Arul and Pachiappan Perumal, "Gc-Ms analysis of bio active components and synthesis of gold nanoparticles using Chloroxylon swietenia DC leaf extract and its larvicidal activity", Journal of Photochemistry and Photobiology B: Biology., 2015, 148, 1-8.

4. Oxana V. Kharissova.; H.V.Rasika Dias.; Boris I. Kharisov.; Betsabee Olvera Perez.; Victor M. Jimenez Perez, "The greener synthesis of nanoparticles", Trends in Biotechnology., 2013, 31(4), 240-248.

5. Birendra Kumar Bindhani and Ashok Kumar Panigrahi, "Green synthesis of gold nanoparticles using Neem (Azadivachta Indica L.) Leaf Extract and its Biomedical applications". International Journal of Advanced Biotechnology and Research., 2014, 15(3), 457-464.

6. Gopinath K.; GowriS.; Karthika V.; Arumugam A, "Green synthesis of gold nanoparticles from fruit extract of Terminalia arjuna, for the enhanced seed germination activity of Gloriosa superba", J Nanostruct Chem., 2014, 4, 115.

7. D. N. Castillo-Lo'pez.; U. Pal, "Green synthesis of $\mathrm{Au}$ nanoparticles using potato extract: stability and growth mechanism", J Nanopart Res., 2014, 16, 2571.

8. Monalisa Pattanayak and P. L. Nayak, "Green Synthesis of Gold Nanoparticles Using Solanus lycopersicum (TOMATO) Aqueous Extract", World Journal of Nano Science \& Technology., 2014, 3(2), 74-80.

9. Jayanta Kumar Patra.; Kwang-Hyun Baek, "Novel green synthesis of gold nanoparticles using Citrullus lanatus rind and investigation of proteasome inhibitory activity, antibacterial, and antioxidant potential", International Journal of Nanomedicine., 2015, 10(1), 7253-7264. 
10. Maribel G. Guzmán, Jean Dille, Stephan Godet, "Synthesis of silver nanoparticles by chemical reduction method and their antibacterial activity", International Journal of Materials and Metallurgical Engineering., 2008, 2(7), 421-424.

11. Arghya Sett.; Manoj Gadewar.; Pragya Sharma.; ManabDeka and Utpal Bora, "Green synthesis of gold nanoparticles using aqueous extract of Dillenia indica", Advances in Natural Sciences: Nanoscience and Nanotechnology., 2016, 7, 2.

12. Mostafa M. H. Khalil., Eman H. Ismail, Fatma El-Magdoub, "Biosynthesis of Au nanoparticles using olive leaf extract: $1^{\text {st }} \mathrm{Nano}$ Updates", Arabian Journal of Chemistry., 2012, 5(4), 431-437.

13. Marie-Christine Daniel and Didier Astruc, "Gold Nanoparticles: Assembly, Supramolecular
Chemistry, Quantum-Size-Related Properties, and Applications toward Biology, Catalysis, and Nanotechnology", Chem. Rev., 2004, 104(1), 293-346.

14. Anal K. Jha and K. Prasad, "Rose (Rosa sp.) Petals Assisted Green Synthesis of Gold Nanoparticles", J. Bionano Sci., 2013, 7, 1-6.

15. Umesh Kumar Parida.; Birendra Kumar Bindhani.; PadmalochanNayak, "Green Synthesis and Characterization of Gold Nanoparticles Using Onion (Allium cepa) Extract", World Journal of Nano Science and Engineering., 2011, 1(4), 93-98.

16. Mohamed Habib Oueslati.; Lotfi Ben Tahar.; Abdel Halim Harrath, "Catalytic, antioxidant and anticancer activities of gold nanoparticles synthesized by kaempferolglucoside from Lotus leguminosae", Arabian Journal of Chemistry., 2018, 4, 443-590. 